\title{
Sustainable Urban Development and Liveability. How can Melbourne Retain its title as the World's Most Liveable City and Strive for Sustainability at the Same Time?
}

\author{
E. Horan ${ }^{1}$, J. Craven 2 ,R. Goulding 3 .
}

\begin{abstract}
Melbourne is a sprawling city of 4.25 million people dispersed, end to end, across a distance of approximately $100 \mathrm{~km}$. The population is growing by 2000 each week. The spread of urbanisation results in the transport task of moving people and goods representing the second largest of the City's Greenhouse gas emissions behind stationary energy generation. If the City is to approach a sustainable transport system it cannot continue in this vein.

This surging population is placing considerable strains on the City's infrastructure. A lag in urban planning and investment in infrastructure is resulting in substantial traffic congestion on freeways, city access points and major arterial roads. The public transport system is overcrowded at peak periods. This population growth pressure is also reflected in other areas such as social and health aspects where, for example, long delays can be experienced at hospital emergency wards. Amid the backdrop of these stresses and strains, Melbourne consistently rates highly as one of the World's Most Liveable Cities- usually in the top three. Melbourne again was crowned the title of the World's Most Liveable City in 2013.

Melbourne is a young city by world standards yet has a proud history developed by its forefathers in planning such attributes as large areas of parkland, pure and fresh water supply, clean air etc. This paper examines these issues in the light of sustainability and liveability. Can the two attributes learn from each other or are they in conflict for modern urbanisations? Is Melbourne growing too quickly? While yet not a megacity along the scale of Tokyo, Beijing or London, it will be in the future and failure to plan for that scenario will have greater detrimental effects than recently being experienced.

Right across the world, megacities are magnets drawing rural populations to the urban centres. The paper also investigates this phenomenon in the light of the sustainability of future urbanisation in contrast to possible alternative urbanisation of towns and smaller settlements around large regional centres. The concept of satellite urbanisation could be applied to Melbourne to relieve the growth pressures on the city and revitalise rural areas many of which are experiencing economic and population decline.
\end{abstract}

Key words: liveability, sustainable urbanisation, mobility, greenhouse gas emissions

\section{Introduction}

Many cities across the world are experiencing extraordinary growth and Melbourne is the fastest growing city in Australia. This growth need not necessarily be a 
problem unless there is insufficient attendant growth of infrastructure to support it. While experiencing this growth, Melbourne has been again announced as the World's Most LiveableCity now for the third year in a row. However, the rapid growth in Melbourne, and the projected population in the next 30 years place severe pressure on the developmental future of Melbourne. Of the top ten most liveable cities, only two are over 2 million and one over 6 million (Department of Transport, Planning and Infrastructure, 2013). This reinforces the severity of the situation and highlights the need to analyse the probable effects the increase in population can have on Melbourne and develop a strategy that will provide for sustainability into the future.With the various 'push and pulls' influencing Melbourne, planning for the future will be a complex task. Meeting the demand for transport will be one of the most complex aspects of planning for Melbourne and its peri-urban environment. Melbourne's most recent infrastructure development is a major road tunnel connecting two freeways across the north of the City.This project is yet another road development and it is time to re-evaluate the viability of road projects as a whole and the role that they play in a city's future. Sustainability is the emphasis of this investigation. Current growth trends need to be examined and howthese impact theshape of the urban pattern of Melbourne. Melbourne is shaped by its transport infrastructure and it is timelyto review how the transport system can be used to derive a sustainable urban network for Melbourne, its peri-urban environment and also to reach out to rural satellites within a short travel time from the greater city of Melbourne.

\section{The Development of Melbourne}

Melbourne was founded in the mid-nineteenth century. The CBD was planned with a meticulous grid of main streets and the inner suburbs spread from there. A tram based transport system assisted the growth of the middle ring suburbs around the turn of the $20^{\text {th }}$ century. From then in conjunction with the tram network a radial heavy rail network spreadto the outer suburbs.

Since WW2 rapid development occurred between those heavy rail lines radiating out from the CBD. This in-fill development was solely road based with the car dominating the transport task.

Melbourne's Planning Strategy (Department of Transport, Planning and Infrastructure, 2013) identifies Melbourne as a sprawling city of 4.25 million people dispersed end to end, across a distance of approximately $100 \mathrm{~km}$. The population increase has been estimated as 2000 each week (Colebatch, 2013).The spread of urbanisation results in the transport task of moving people and goods representing the second largest of the City's Greenhouse gas emissions behind stationary energy generation. If the City's transport system is to approach sustainability it cannot continue in this vein.

Melbourne has retained a dominant CBD as a mono-centric city focusand has become one of the most sprawling cities in the world. The low population density of Melbourne in comparison with other world cities is demonstrated in the report, Melbourne - a changing and growing city (Department of Transport, Planning and Local Infrastructure 2013). 
Figure 1 shows how the population density around the inner city area is predominantly medium density and becomes considerably less dense further away from the city centre.

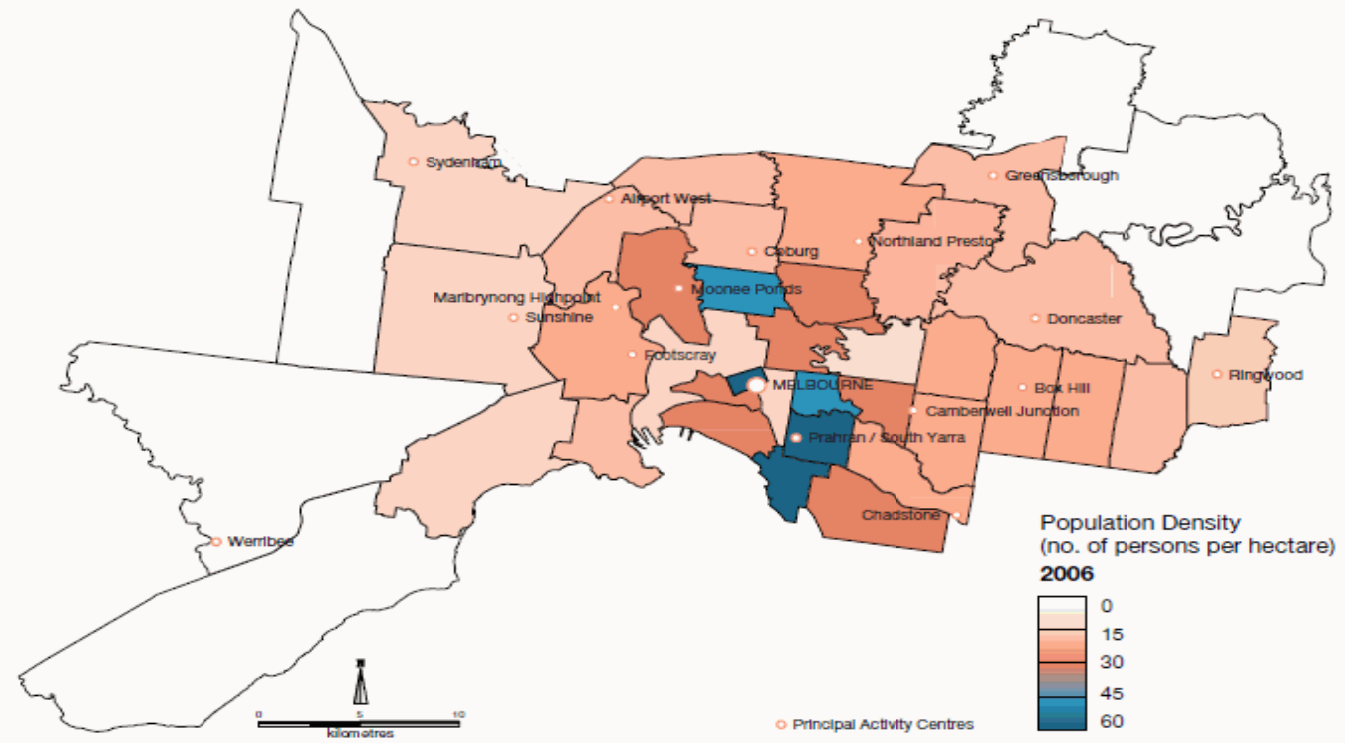

Figure 1. Population density of Melbourne 2006 Source: (Department of Transport, Planning and Local Infrastructure, 2013).

This sprawling development has been driven by the car and subsequent investment in road based infrastructure at the detriment of the enhancement of public transport. The use of the transport infrastructure in Australian capital cities and the reliance on the car is alarmingly illustrated in Figure 2.

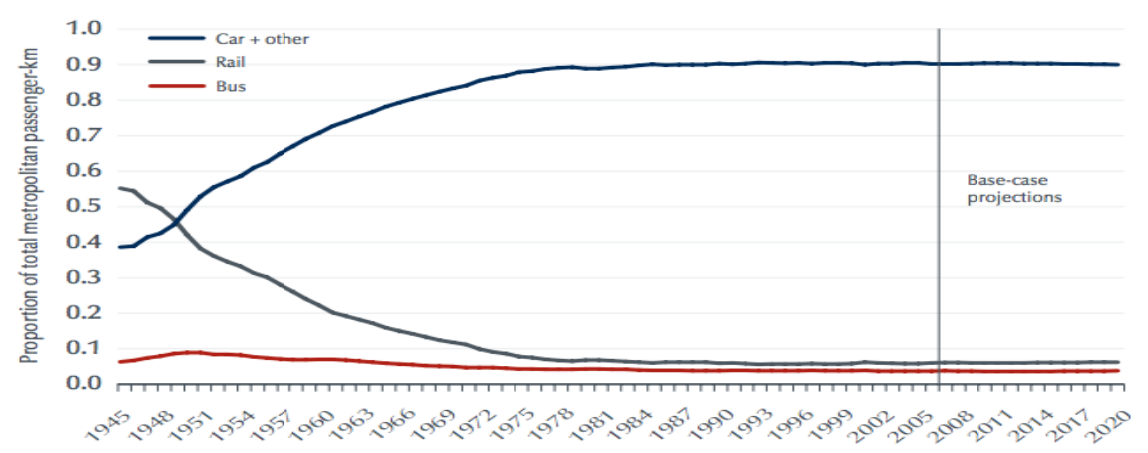

Figure 2: Historical and projected modal share, Australian metropolitan passenger travel, 1947-2007 Source: (Bureau of Transport and Regional Economics, 2007).

However, even the extensive road based investment has not kept pace with demand. Now all transport infrastructure capacity is under severe pressure. Over the last decades population and urban development have increased without the attendant improvement in infrastructure. Increased apartment development has occurred in the established inner 
and middle ring suburbs. These areas were blessed with a good supply of transport. Nevertheless, these areas are under increasing strain from traffic congestion and public transport being under capacity at peak periods.

\section{Population Trends}

The population of Melbourne is growing at a vigorous rate. This increase can be viewed in the light of worldwide population growth. The world is experiencing an unprecedented shift in population from rural areas to urban centres. The UN Population Division demonstrates the global shift in rural to urban environments and in 2009, for the first time in human history, urban populations surpassed rural populations (United NationsDepartment of Economic and Social Affairs/Population Division, 2012).

This worldwide trend is reflected in similar data from the State Government of Victoria. Figure 3 below demonstrates how Melbourne dominates population in the State.

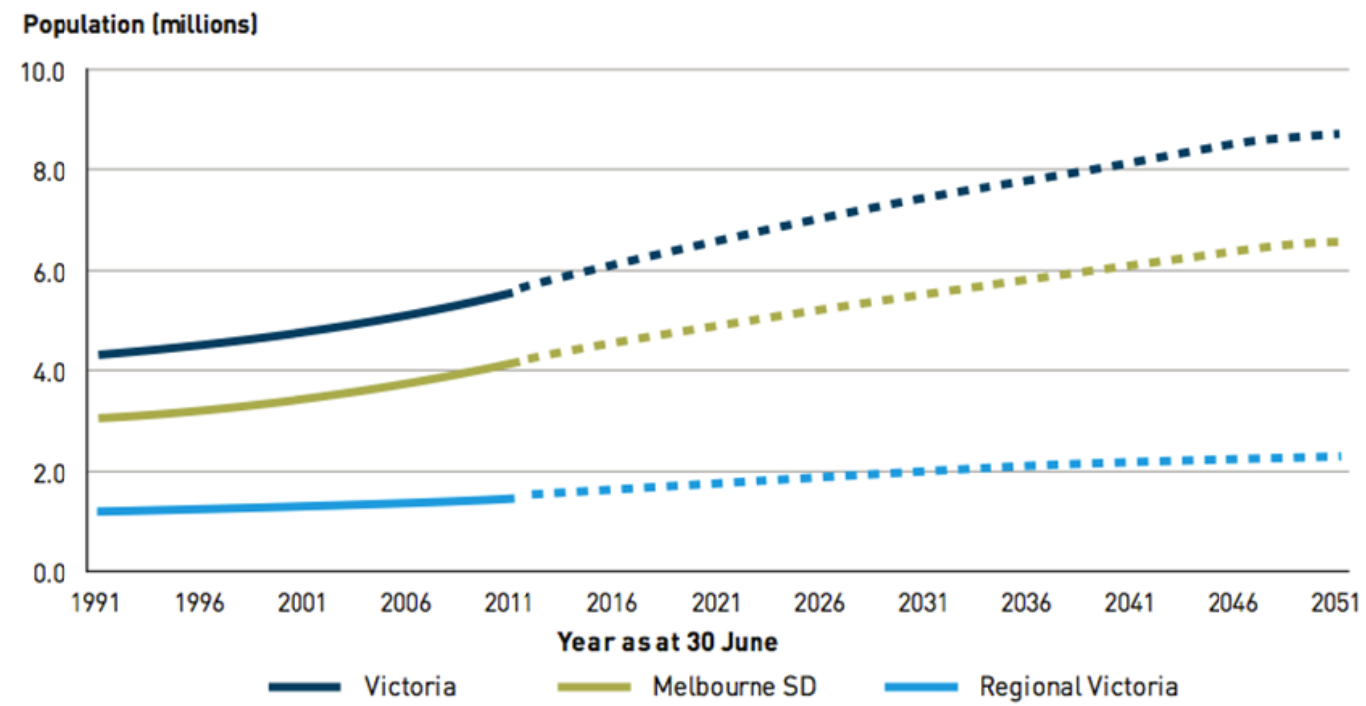

Figure 3: Historical and Projected Population, Victoria, Melbourne SD and Regional Victoria, 1991-2051 Source: (Victorian State Government - Department of Planning and Community Development, 2012)

These trends indicate that Melbourne's unprecedented growth is not seen as diminishing in the future with the population set to almost double in the next 40 years. And in comparison, regional population will only increase marginally.

In their paper on the future of small settlements, Tozzi and Horan (2012) discuss how the world is currently experiencing the greatest human migration in history. Megacities of 10 and 20 million and more are emerging. In contrast small settlements,rural towns and regions are experiencing a steady drain of human capital. This shift in migration is raising socio-economic and sustainability issues in developed countries as well as the developing world. These issues are impacting rural areas of Australia with the hollowing 
out of the younger population cohort, as young people are attracted to the cities such as Melbourne (Tozzi\& Horan, 2012).

\section{Pressures on Infrastructure}

After WW2 local communities, cities and states focused on developing infrastructure. People had lived through the Depression and the war and there was a strong desire to improve the quality of life and this drive for progress was expressed through the development of infrastructure. In those first decades following WW2, government organisations based in Melbourne such as the Melbourne Metropolitan Board of Works and the State Electricity Commission implemented major infrastructure works such as dams, freeways, open cut coal mines and power plants.

Government authorities had a strong revenue base from the service they provided. Not only did they have this secure income but they were in a position to raise funds via special bond issues. Through these mechanisms they could plan for and develop major infrastructure projects. During the 1980's this method of infrastructure development by public authorities became perceived as over-governing and shutting the door on private industry even though the major cost of construction was let to private industry through the tender process. Nevertheless, the market economy concepts of Thatcherism and Reaganism influenced the burgeoning private investment in infrastructure.This was demonstrated through the growth in'private-public-partnership' and 'build, own, operate and transfer' methods of bringing public infrastructure projects to fruition.

Increasingly, government has withdrawn from direct involvement with infrastructure. The tax base has changed also - becoming more centralised. The states have less opportunity for raising funds as central government has introduced a blanket 'goods and services tax' and then distributes funding back to the states. This vertical fiscal integration of the tax system has also meant the city and state have less influence on the purse strings. Conversely, decisions about major infrastructure in cities become more under the purview of the national government which is distant from the localised infrastructure problems where the action needs to occur. National governments also see their priorities elsewhere such as in national demands on budgets on such things as health, welfare and education rather than improving local infrastructure capacities.

All in all these issues have led to a kind of paralysis by government from national down to the local level. National governments are distant from local infrastructure problems and have priorities on national issues. Local and state governments no longer have direct access to funding and have lost the taste for direct involvement in infrastructure provision since private investment companies have moved into the space.

\section{Liveability}

The liveability of cities has become a much discussed topic. There are various measures and indices promoted which allocate rankings of a liveability Index (LI) to cities across the world. The rankings become news items when released and become an important part of the promotion material for top ranking cities. The two main indices are 
published by the Economist Intelligence Unit (EIU 2013) and Monocle, the lifestyle magazine.

The EIU Liveability Index provides an indication of the level of development and consequently lifestyle of the city. The index ranks 140 world cities over a range of over 30 quantitative and qualitative measures. Five broad categories are applied: stability; healthcare; culture and environment; education; and infrastructure.

Melbourne consistently rates highly - usually in the top three - of the World's Most Liveable Cities. Melbourne, again was crowned with the title of the World's Most Liveable City in 2013.

Melbourne is a young city by world standards yet has a proud history developed by its forefathers in planning such attributes as large areas of parkland, pure and fresh water supply, clean air etc. This high liveability rating could be summarised as a high lifestyle quality component. The high ranking will come under pressure along with increased transport congestion and decreased environmental quality. Is Melbourne growing too quickly? While yet not a megacity along the scale of Tokyo, Beijing or London, it will be a megacity of the future and failure to plan for that scenario will have even greater detrimental effect than recently being experienced.

Transport and environment are major components of the LI. If these receive lower scores, the LI will be rated lower thus affecting Melbourne's world ranking. This could have negative impacts on tourism and people and firms decisions to live or invest there in turn producing a negative impact on the economy of the whole city.

\section{Sustainable Urbanisation}

As a response to concern over Melbourne's ability to maintain its very high liveability index, a new emphasis to meeting congestion problems and planning for population growth into the future is proposed through an alternative more sustainable approach to the provision of transport infrastructure and urban development.

As discussed previously Melbourne has a very low urban density yet increasingly it is experiencing transport congestion. Rail is generally considered not to be viable for low density areas of a city in a conventional transport planning context.(Committee for Perth, 2011). Furthermore, the delivery of traditional Transit Orientated Development (TOD) principles within a low density urban setting is challenging. This is because TOD principles are based around high density living concentrating mixed land uses at railway stations.

One example of a rail system that has been delivered successfully in very low density urban environments over a sprawling urban corridor is the Southern Railway from Perth Australia (Committee for Perth, 2011). Opening in 2007, the Perth Southern Railway stretches $72 \mathrm{~km}$ from the Perth CBD to Western Australia's second largest city at Mandurah. The catchment density is mainly between $6-15$ dwellings per hectare and this density provided considerable controversy initially as it is a very low dwelling density for rail-based public transport services to be considered viable (McIntosh et al., 2013). This public transport system was designed to directly compete in terms of journey time and cost with private vehicle transport and this factor was another major difference from other public transport systems in Australia(Curtis and Mellor, 2011). This was due to 
very high car dependency in the areas where the railway was proposed presenting a major challenge to the uptake of public transport.

A transit-transfer model was developed to compete with the car in the low density areas servicing the railway, providing people in surrounding areas with good access to railway stations through high quality bus interchange and good car access and parking (Curtis and Mellor, 2011). This model for low density areas, whereby passengers are brought to the railway through bus and car has been described by Waldock in What We Thought Would Kill Us, The Evolution of Perth's Passenger Rail(as cited in Committee for Perth, 2011), as '.... new model for rail which has become a touchstone for the industry nationally'. It differs from the typical public transportation model of mass transit, which achieves mass through penetration into high urban densities. This is also very different from the traditional TOD concepts based around walk on patronage (Curtis \& Mellor, 2011). These Southern Railway station precincts act primarily as a transit interchange (rather than a destination station) aiming to achieve a high level of accessibility by car and feeder bus, with no attempt to develop land use activity to support the station (Curtis and Mellor, 2011; Olaru et al., 2011). In contrast, at other stations more traditional TOD models have been adopted; in one case the Government planned for a new TOD community to support walk on rather than car patronage. Other stations sit somewhere between these two extremes. Curtis and Mellor (2011), explain that these different models '...present an opportunity to explore the various ways of integrating the railway with land use and so to test the concept for transit-oriented development in a low-density suburban environment'.

In terms of patronage the Southern Railway has been very successful, carrying over 70,000 people per day (five times the patronage on the bus service it replaced) and has reached the patronage levels predicted for 2021 a decade ahead of time (McIntosh et al., 2013). A major part of the success of the rail system appears to be the bus interchange model, which transfers patrons from the bus service to rail. This is clear considering $85 \%$ of the Southern Rail patrons access the train by a bus service, (or line to line transfer), whereas around $8 \%$ are from the park and ride and the remainder from pedestrian catchment and kiss and ride (Western Australia Department of Planning 2011 as cited in McIntosh et al., 2013). Careful integration of bus services, the use of integrated ticketing and fares without transfer penalties have been crucial to the success of this model, ensuring time and cost remains competitive with the motor vehicle (McIntosh et al., 2013). Another crucial aspect in the success of the railway is the high speed of the system when compared to competing car based trips (McIntosh et al., 2013). For instance, the railway has a maximum speed of $137 \mathrm{~km} / \mathrm{hr}$. and an average speed of approximately $90 \mathrm{~km} / \mathrm{hr}$. compared with a typical suburban rail system, which in Australia averages around $40 \mathrm{~km} / \mathrm{hr}$. (if stopping at all stations) (McIntosh et al., 2013). The successful interchange model and the high speed nature of the rail service has cut the journey time from approximately 68 minutes to 48 minutes for the journey from Mandurah to Perth when compared to a private car (McIntosh et al., 2013; Waldock, 2007). Furthermore, McIntosh et al., 2013, demonstrates that the public transport trip can provide a lower generalized cost for the trips to the CBD than the private car.

The Southern Railway has been a catalyst for new development in the railway precincts. Indeed, many property developers chose to promote access to the railway as a key draw 
card in their development For example billboardsdisplaying the proposed train used the railway to promote a new development in Wellard (one of the railway catchment areas) (Curtis, 2008). This included redevelopment opportunities to re-orient existing urban areas toward the station (Olaru et al., 2011). In new areas, the government and private sector planned for new TOD communities at some railway precincts, thus increasing accessibility and economic opportunity. For example, at Wellard station, located 39 kilometers from the Perth CBD, land was set aside for a TOD community designed on 'new urbanist' and TOD principles (Olaru et al., 2011). Development of a mixed use main street (including $4070 \mathrm{~m} 2$ of retail space) centered on the station surrounded by higher density residential dwellings was planned (Olaru et al., 2011). A street network supporting a good pedestrian environment and access was part of the design. Construction of the Southern Railway through the city also proved to be a major catalyst for redevelopment in the city centre, being a major driver for proposals such as the Perth Waterfront and Northbridge Link (Committee for Perth, 2011).

On a positive note more recent research indicates that a change in emphasis may be emerging. Presently there is a dramatic peaking in car use and associated increase in the world's urban rail system, including in the traditional car dependent cities of the US and Australia (Newman et al., 2013). Public transit patronage in Australia is growing faster than car usage in virtually every major city in Australia and car usage per capita is now falling in many cities. Newman et al(2013), provide new data demonstrating a plateau in the speed of urban car transportation, which he suggests is a major contributing factor to the rise of rail, which can be (as demonstrated in the Perth case study) a faster mode of transport. Newman et al (2013) suggest various other structural, economic and cultural changes that are likely to be contributing to the move away from car dependent urbanism. For example, it is suggested that a peak in car use is also due 'to the growing value of dense knowledge based centres that depend on rail for their viability and cultural attraction' (Newman et al., 2013). In order for Melbourne to capitalise on this new trend there are important lessons to be learnt from examples in Europe and particularly the Perth Southern Railway in designing urban rail systems for making travel in dispersed cities such as Melbourne more sustainable.

Melbourne could do much worse than review the successes of the Perth-Mandurah Southern Railway. As the line stretches over $70 \mathrm{~km}$ into the Perth surrounds, a similar scenario can be painted for Melbourne and its surrounds. Melbourne has many small settlements and rural towns within and around a radius of approximately $100 \mathrm{~km}$. Many of these already have rail links to Melbourne. These areas should be examined closely to determine the viability of enhancing the rail network and local catchment feeder routes. With a good transport link increased urbanisation could be envisioned to occur in these regional areas.

Not only would this satellite urbanisation ease the burden on Melbourne's infrastructure but it would revitalise the currently declining rural regions. Horan et al (2014) discuss how improving transport infrastructure and communications links enhances access to and awareness of regional areas. They demonstrate how across the world in recent times rural areas have experienced sometimes dramatic decreases in population as migration to urban centres occurs. Traditional industries such as agriculture and associated services are impacted and the sustainability of these settlements is at risk. In contrast those areas 
which have focused on their point of difference whether that be local produce, history or specialist activities and nature based tourism etc have been able to build an independent economy which has eventually led to increased population and sustainability. Melbourne, as well as being the World's Most Liveable City, has a hinterland blessed with natural beauty and vibrant local rural businesses. This hinterland, with enhanced transport infrastructure, has the potential to be part of an extendedinter-connected satellite urbanisationlinked to Melbourne that would be a very special asset to the whole State of Victoria and Australia.To complement this system, new mobility strategies, including those based on E-mobility, at the local level, feeding into sustainable transport systems for the longer transit to regional and urban centres should be investigated.

\section{Conclusion}

Melbourne is a sprawling city of 4.25 million people dispersed end to end across a distance of approximately $100 \mathrm{~km}$. The population is growing by 2000 each week. The spread of urbanisation results in the transport task of moving people and goods representing the second largest of the City's Greenhouse gas emissions behind stationary energy generation.

This sprawling development has been driven by the car and subsequent investment in road based infrastructure at the detriment of the enhancement of public transport. However, even the extensive road based investment has not kept pace with demand. Now all transport infrastructure capacity is under severe pressure. Over the last decades population and urban development have increased without the attendant improvement in infrastructure. While once blessed with a good supply of transport, inner suburbs, middle areas and outer suburbs across Melbourneare under increasing strain from traffic congestion and public transport is under capacity at peak periods.Melburnians are experiencing ever increasing travel times. Even with this pressure on the transport system Melbourne consistently rates highly as one of the World's Most Liveable Cities usually ranking in the top three. Melbourne, again was crowned with the title of the World's Most Liveable City in 2013.

With a view to meeting Melbourne's transport needs and proposing a strategy for sustainable urbanisation in the future, the Perth-Mandurah Southern Rail stretching over $70 \mathrm{~km}$ from Perth is examined. This project demonstrates the benefits that public transit can produce.Melbourne is especially blessed with a hinterland abundant with natural beauty and vibrant local rural businesses. This hinterland, with enhanced transport infrastructure, has the potential to be part of an extended inter-connected satellite urbanization linked to Melbourne which would be a very special asset to the whole State of Victoria.

\section{References}

Bureau of Transport and Regional Economics (BTRE) (2007).Estimating urban traffic and congestion cost trends for Australian cities; Working paper 71. Canberra ACT:BTRE.

Colebatch, T. (2013, September 27). State grows by 100,000 people a year.The Age Newspaper, Melbourne. 
Committee for Perth (2011).What We Thought Would Kill Us, The Evolution of Perth's Passenger Rail, Perth WA: Committee for Perth.

Curtis, C. (2008). Evolution of the Transit-orientated Development Model for Low-density Cities: A Case Study of Perth's New Railway Corridor.Planning, Practice and Research, 23(3), 285-302.

Curtis, C. \& Mellor, R. (2011). Anticipating a New Railway: The Relevance of Transit-Orientated Development to Businesses in a Car-Orientated City, Urban Policy and Research, 29(2), 141-165.

Department of Planning and Community Development (2012). Victoria in the Future 2012:Population and Household Projections 2011-2031 for Victoria and it's Region, Melbourne Vic: Spatial Analysis and Research.

Department of Transport, Planning and Local Infrastructure (2013). Investing in Transport - Chapter 1: Melbourne - a changing and growing city.

Department of Transport, Planning and Local Infrastructure (2013).Plan Melbourne: Metropolitan Planning Strategy, Melbourne VIC: Victorian Government Printer.

Global Liveability Ranking and Report August 20132013 The Economist Intelligence Unit.

Horan, E., Goulding, R. \&Tozzi, L. (2014). The importance of sustainable tourism in reversing the trend in the economic downturn and population decline of rural communities. Journal of Tourism and Cultural Heritage,RURAL TOURISM EXPERIENCES of PASOS, 12(3).

McIntosh, J., Newman, P. \&Glazebrook, G. (2013). Why Fast Trains Work: An Assessment of a Fast Regional Rail System in Perth, Australia.Journal Of Transportation Technologies, 3, 37-47.

Newman, P., Kenworthy, J. \&Glazebrook, G. (2013). Peak Car Use and the Rise of Global Rail: Why This Is Happening and What It Means for Large and Small Cities.Journal Of Transportation Technologies, 3, 272-287.

Olaru, D., Smith, B. \&Taplin, J.H.E. (2011). Residential location and transit-orientated development in a new rail corridor.Transportation Research Part a,45, 219-237.

Tozzi, L \& Horan, E. (2012). Do Small Settlements Offer a Sustainable Alternative to the Growing Emergence of Megacities? A Comparison of the Socio-economic Sustainability of Small Settlements in Europe and Australia,International Journal of Arts and Sciences. 5(6). 461-477.

United NationsDepartment of Economic and Social Affairs/Population Division (2012).World Urbanization Prospects: The 2011 Revision: Highlights, New York NY: United Nations

Waldock, R. (2007). Presentation to the Urban Development Institute of Australia Sustainability Forum: Options for Sustainable Transport, Public Transport Authority, WA, Retrieved from http://www.udiawa.com.au/Uploads/File/PDF/Event $\% 20$ Archives/2007/UDIA\%20Sustainabil ity $\% 20$ Conference $\% 20$ September $\% 202007 /$ Reece $\% 20$ Waldock, $\% 20$ PTA.pdf 